doi: $10.15407 /$ ujpe61.11.1008

A.S. TONKOSHKUR, A.YU. LYASHKOV, A.V. DEGTYARYOV

Oles Honchar National University of Dnipropetrovsk, Chair od Radioelectronics

(72, Gagarin Ave., Dnipropetrovsk 49050,Ukraine; e-mail: vdnu@yandex.ua)

PACS 72.80.Le, 72.80.-r, SIZE EFFECTS IN ELECTRICAL PROPERTIES 82.35.Np \title{
OF CARBON-POLYPROPYLENE COMPOSITES
}

\begin{abstract}
The temperature dependences of the resistance, current-voltage characteristics, and dielectric spectra of composites based on polypropylene and fillers made of micro- and nano-sized carbon particles have been studied. A reduction in the average size of conducting filler particles is found to decrease the resistivity magnitude, to shift the posistor section in the current-voltage characteristics toward lower electric fields and larger currents, and to increase the low-frequency dielectric permittivity of the researched composites. It is shown that these "size"effects can be explained by a growth of the effective fraction of the volume occupied by the conducting filler owing to the emergence of interfacial boundary layers in the polypropylene matrix. The electric properties of the layers differ from those for bulk polyethylene, and charge carriers can move in them. In other words, a change in the size of carbon particles gives rise to changes in the specific area and the effective fraction of the conducting filler.

Ke ywords: composite, carbon filler, conductivity, dielectric permittivity, interphase layer.
\end{abstract}

\section{Introduction}

Electric properties of polymeric composite materials can be varied in rather wide limits. This is one of their advantages in comparison with traditional inhomogeneous materials that are used as the element base of modern electronics, such as condenser [1,2], varistor $[3,4]$, and posistor ceramics [5-9]. As a result, polymer composites with different characteristics can be obtained on the basis of the same initial substances. However, for the purposeful control over their properties and the development of materials with required sets of parameters, one has to know those factors that govern the variation of the main electrophysical properties of such materials. In spite of the fact that a considerable number of theoretical and experimental works in the scientific literature deal with some of the indicated issues [10-14], there are no systematic results and regularities that would relate the fabrication methods, structure, and electric parameters of such complicated systems with one another.

Particles of technical carbon are assumed to create a structural net in the polymer. Some researchers concur that a transient polymer layer with specific

(C) A.S. TONKOSHKUR, A.YU. LYASHKOV,

A.V. DEGTYARYOV, 2016

1008 mechanical and physico-chemical properties emerges on the surface of technical carbon particles [1519]. The properties of the polymeric material in those layers gradually change from the destructured state to the natural one, which becomes restored at a certain distance from the surface of filler particles. Some of the cited authors distinguished several polymeric layers with different properties near the particle surface - for example, hard and viscous - and associated the properties and the behavior of a composite material with the peculiarities in the behavior of polymeric chains in the viscous layer $[15,17,19]$.

The results of researches concerning the electric conductivity in the considered composites are usually interpreted in the framework of percolation theory [12,20-24], and their dielectric properties are analyzed on the basis of ideas of an interlayer polarization of the Maxwell-Wagner type [25-29]. The both interpretations are based on a model of two-component systems, which ignores the presence of transient layers with the electric properties distinct from those of a polymer. Concepts describing the specific electric properties of those layers have not been developed enough. They were used only in a few works, while analyzing the relationship between the dielectric permittivity of a composite and the concentration of a conducting filler in it [30-34].

ISSN 2071-0194. Ukr. J. Phys. 2016. Vol. 61, No. 11 
In this work, the results of our researches concerning the features in the temperature dependences of the resistance, current-voltage characteristics, and dielectric spectra of the composites fabricated on the basis of polypropylene and fillers with micro- and nano-sized carbon particles are reported. The aforementioned electric properties are interpreted as a manifestation of the participation of transient layers in their formation.

\section{Specimens and Experimental Technique}

Secondary granulated polypropylene and a conducting filler were applied as the initial components of the composite. As a conducting filler, natural graphite with grain dimensions of about $10 \mu \mathrm{m}$ or nano-sized technical carbon blacks N220 and N550 with particle dimensions of about 20 and $50 \mathrm{~nm}$, respectively, were used.

The polypropylene-carbon composites were synthesized, by following a technological procedure close to that known for posistor elements of the Polyswitch type [35]. The mixture of polypropylene and the filler was heated up to the polymer transition into the viscous fluid state and was mechanically mixed. After the cooling, the piece was crushed until the particle dimensions reached $50 \mu \mathrm{m}$.

The obtained blend was pressed under a pressure of $20 \mathrm{MPa}$. The specimens were fabricated in the form of disks $1-3 \mathrm{~mm}$ in thickness and $10 \mathrm{~mm}$ in diameter. They were heated at the melting temperature of crystalline polypropylene $\left(\approx 170{ }^{\circ} \mathrm{C}\right)$ and a pressure of $0.1 \mathrm{MPa}$ for $1 \mathrm{~h}$. Thin copper nets impressed into the specimens served as electrodes.

The specimen microstructure was similar to that of isotropic composites of this kind. The composite material was a heterogeneous system, in which the particles of the conducting component with different shapes and orientations were arranged in the insulating matrix, polypropylene.

The dependences of the electric resistivity and the current-voltage characteristics were measured using standard methods. The specimen was arranged in a screened measuring chamber. The data were registered after a thermodynamic equilibrium between the researched specimen and the environment was established.

The dielectric parameters were studied in a radiofrequency range (from $50 \mathrm{kHz}$ to $10 \mathrm{MHz}$ ) on a
Q meter VM-560. Our researches of near-electrode phenomena showed that the measured electric parameters were governed by the bulk properties of specimens.

\section{Experimental Results and Their Discussion}

\section{1. dc conductivity of composites}

3.1.1. Temperature dependences of specimen resistance

In Fig. 1, the temperature dependences of the dc specific resistance of composite specimens, $\rho_{0}$, for various volume fractions of carbon fillers are exhibited. One can see that the composites demonstrate posistor properties: their electric resistance grows with the temperature. The positive temperature coefficient of the resistance in the considered composite structures can be interpreted in the framework of general notions about percolative conductivity $[36,37]$ as a result of breaks in the electric current circuits formed by particles of the conducting phase owing to a drastic increase of the polymeric matrix volume with the temperature. For the studied specimens, the relevant parameter varied within an interval of $0.1-0.2 \mathrm{~K}^{-1}$.

A comparison of the temperature dependences $\rho_{0}(T)$ reveals a specific "size effect": the dependence of the absolute values of electric resistivity in the studied composites on the average size of filler particles, provided that all other conditions remain the same. As follows from Fig. 1, if the volume fractions of the carbon filler, $\nu$, is relatively small, a substantial difference between the electric resistances for composite specimens on the basis of micro- and nano-sized particles is observed (Fig. 1, a). At larger $\nu$-values, the influence of particle dimensions becomes weaker (Fig. 1, b).

\subsubsection{Dependence of specimen resistance on the filler volume fraction}

In Fig. 2, the dependences of the dc resistivity of the examined composites, $\rho_{0}$, on the volume fraction of the carbon filler with various particle sizes are depicted. The dependences have a form typical of composites with conducting fillers: if the volume fraction of a filler increases, the resistivity $\rho_{0}$ decreases. However, the values of $\rho_{0}$ for composites on the basis of nano-sized particles are lower in the con- 


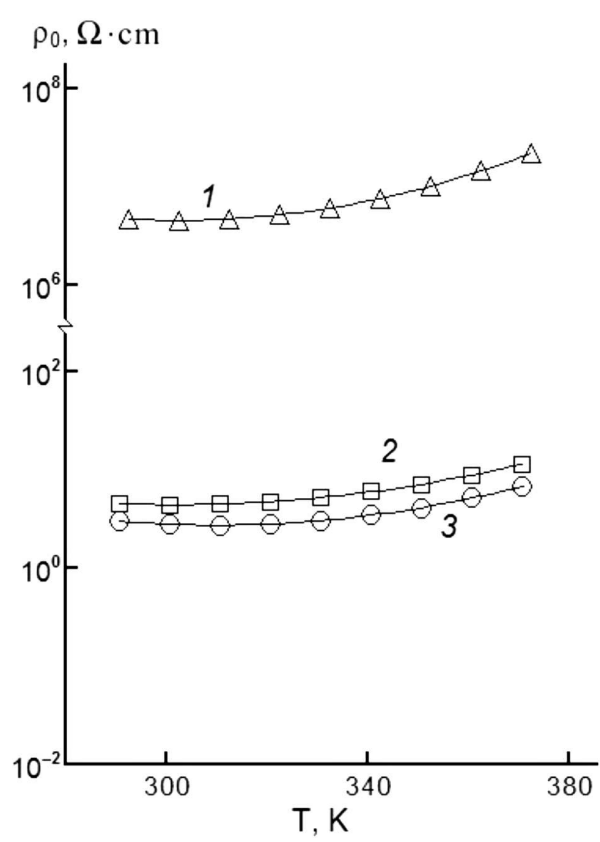

$a$

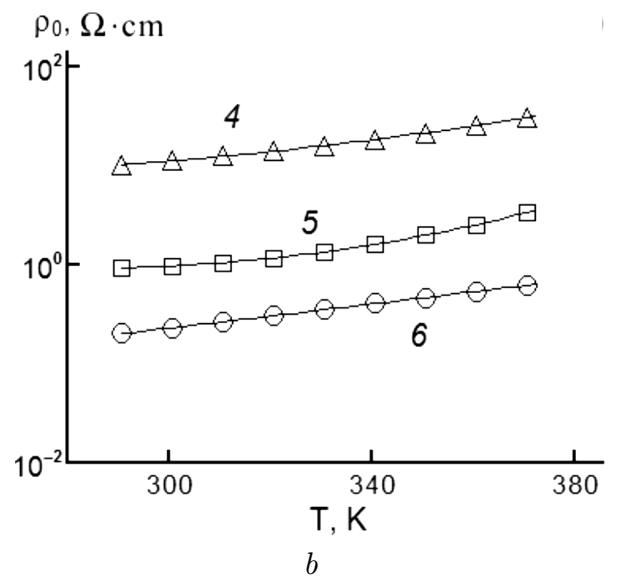

Fig. 1. Temperature dependences of the specific resistance $\rho_{0}$ of polypropylene-carbon composite specimens with the carbon filler volume fractions $\nu=0.044(a)$ and $0.095(b)$. The carbon fillers were fabricated on the basis of micro- $(1,4)$ and nanosized particles of carbon blacks N550 (2, 5) and N220 (3, 6)

sidered interval of volume fractions $\nu$. The magnitude of specific resistance decreases, as $\nu$ grows, more rapidly for composites with smaller dimensions of carbon particles.

\subsubsection{Current-voltage characteristics}

The current-voltage characteristics for the studied specimens of polypropylene-carbon composites are

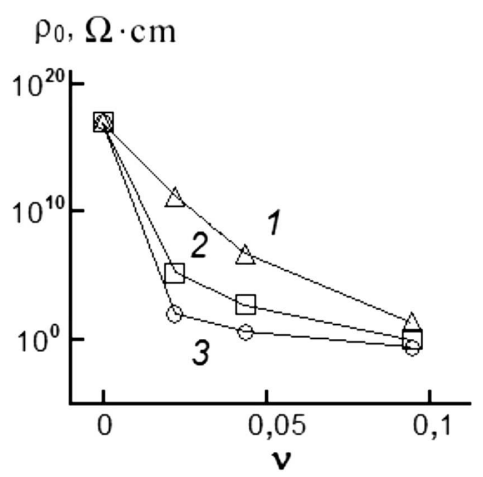

Fig. 2. Dependences of the specific resistance of composites, $\rho_{0}$ on the volume fraction of the fillers fabricated on the basis of micro- (1) and nano-sized particles of carbon blacks N550 (2) and N220 (3). The temperature $T=300 \mathrm{~K}$

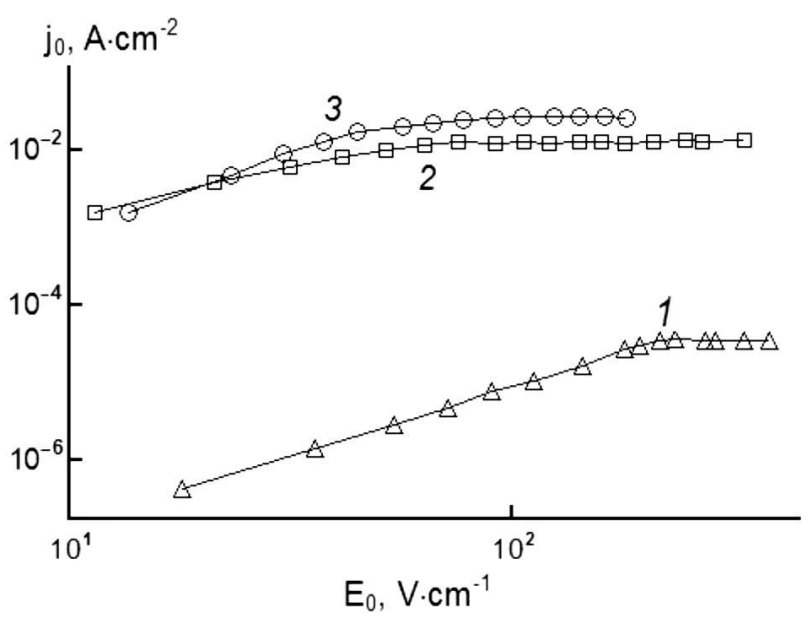

Fig. 3. Current-voltage characteristics for the specimens of polypropylene-carbon composites on the basis of micro- (1) and nano-sized particles of carbon blacks N550 (2) and N220 (3) with $\nu=0.022$

shown in Fig. 3. They have a form typical of posistor composites. With the growth of the applied voltage, the thermal power released in the specimen increases, and the specimen is heated up, which gives rise to the thermal expansion of the matrix polymer and the breaks in the percolative electric current channels.

The current-voltage characteristics also demonstrate the aforementioned "size effect". First, a substantial growth of the electric current density through the specimen is observed, when the size of carbon filler particles diminishes. Second, the interval of electric fields corresponding to the stabilization and a subsequent decrease of the current through such a po-

ISSN 2071-0194. Ukr. J. Phys. 2016. Vol. 61, No. 11 
sistor becomes shifted toward lower voltages for the specimens with smaller (nano-sized) carbon particles.

The experimental data presented above testify to a considerable dependence of the dc conductivity of composites on the size of conducting filler particles. One of the interpretations of this effect consists in the existence of localized electron states in the polypropylene matrix and the existence of an interphase boundary layer adjacent to the carbon filler particles, with the properties of the interlayer being distinct from the bulk electric properties of polypropylene [30-34]. Therefore, it should be accepted that charge carriers can move in this destructured layer. One of the possible mechanisms was analyzed in works $[30,32]$ devoted to the consideration of the capture of free charge carriers from a conducting (or semiconducting) filler particle onto localized electron states (traps) in a dielectric matrix. Provided this scenario, the volume in the composite specimen, where free charge carriers can move, increases. In such a manner, the "apparent" volume fraction of the filler grows. From this point of view, the experimental results presented above, namely, a higher dc conductivity of composites with smaller carbon filler particles, are a consequence of the growth of the specific filler surface. The larger specific surface of the filler gives rise to the larger volume of the indicated interphase layer and, therefore, to an increase of the "apparent" volume fraction of the filler in the composite. As a result, the percolation thresholds for the conductivity in the considered composites, which are determined with neglect of the phenomena described above, turn out shifted toward lower values

\subsection{Dielectric properties}

\subsubsection{Spectra of the dielectric permittivity} of composites in the radiofrequency interval

Dielectric researches are one of the most effective methods for the revealing of peculiarities in the structure of two-component heterogeneous systems and the relation of this structure with the mechanisms of formation of the conductivity in those systems [38-40]. In particular, the results of corresponding researches make it possible to analyze the manifestations of the effects associated with the formation of transient phases different by their physical properties from the initial components of composites $[30,32,37,38]$.

ISSN 2071-0194. Ukr. J. Phys. 2016. Vol. 61, No. 11

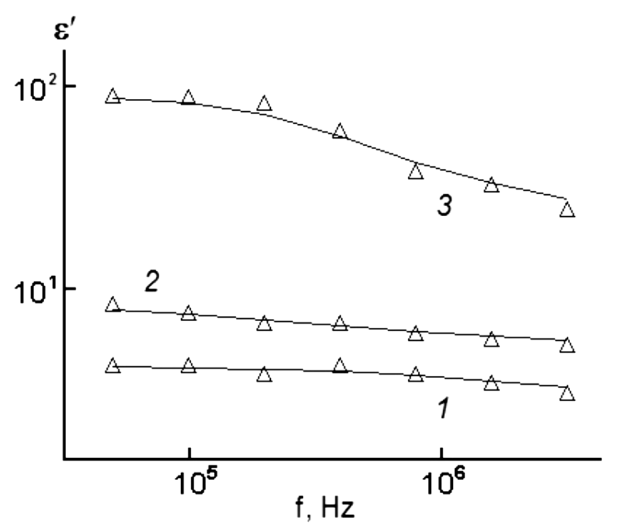

$a$

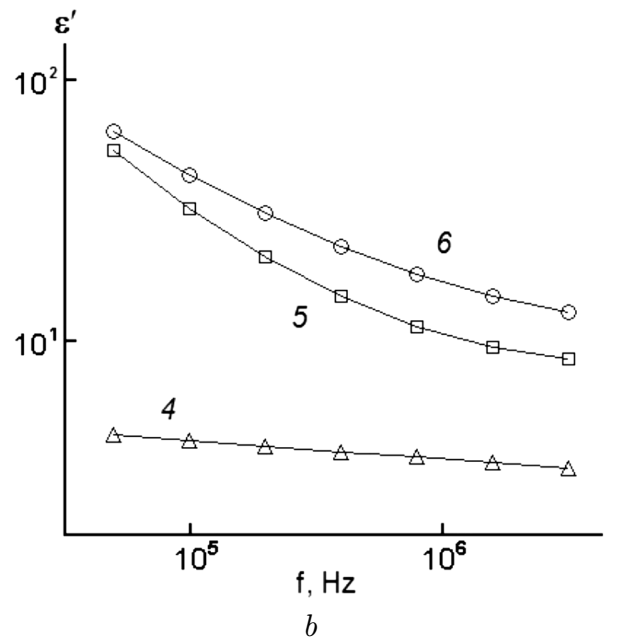

Fig. 4. Frequency dependences of the relative dielectric permittivity $\varepsilon^{\prime}$ for specimens of polypropylene-carbon composites with micro-sized particles and the filler volume fractions $\nu=0.022$ (1), 0/044 (2), and 0.095 (3) (a) and for specimens with micro- (4) and nano-sized particles of carbon blacks N550 (5) and N220 (6) with $\nu=0.022(b)$

Typical frequency dependences of the relative dielectric permittivity, $\varepsilon^{\prime}(f)$, obtained for specimens of the researched composites are depicted in Fig. 4. The curves demonstrate the dielectric dispersion in the whole examined frequency interval. The observed magnitudes of dielectric permittivity considerably exceed its high-frequency value $\varepsilon_{h}^{\prime} \approx 3.0$ determined by the known Bruggeman and Böttcher formulas [41-43] for two-component insulators with the dielectric constants of polypropylene $\left(\varepsilon_{\mathrm{PP}}^{\prime}\right)$ and graphite (or technical carbon black) $\left(\varepsilon_{\mathrm{C}}^{\prime}\right)$. For polypropylene, $\varepsilon_{\mathrm{PP}}^{\prime}=2.2$ [44]. The relative dielectric permittivity of graphite was estimated from the data on the graphite refrac- 
tive index $n_{\mathrm{C}}=1.93 \div 2.07$ [45] using the known relation $\varepsilon_{\mathrm{C}}^{\prime} \approx n_{\mathrm{C}}^{2}$. With the growth of the filler volume fraction, the magnitude of dielectric permittivity increases. The indicated regularities can be considered as an evidence that the Maxwell-Wagner separation of free charge carriers in the conducting filler particles participates in the formation of the composite dielectric permittivity. The arrangement of the corresponding region of the dielectric permittivity dispersion can be determined from the dispersion frequency $f_{d}$. In the framework of the model, in which the matrix contains Wagner spherical conducting inclusions [40], we have

$f_{d} \approx \frac{\sigma_{\mathrm{C}}(1-\nu)}{2 \pi \varepsilon_{0}\left[2 \varepsilon_{\mathrm{PP}}^{\prime}+\varepsilon_{\mathrm{C}}^{\prime}+\nu\left(\varepsilon_{\mathrm{PP}}^{\prime}+\varepsilon_{\mathrm{C}}^{\prime}\right)\right]}$,

where $\varepsilon_{0}$ is the electric constant.

Taking into account that the minimum specific conductance of graphite $\sigma_{\mathrm{C}}=2 \times 10^{1} \Omega^{-1} \mathrm{~cm}^{-1}$ [46], we obtain $f_{d}>10^{12} \mathrm{~Hz}$ for the composites concerned. Therefore, the frequency dependences $\varepsilon^{\prime}(f)$ in Fig. 4 correspond to the low-frequency interval of the considered dielectric dispersion, where the magnitude of $\varepsilon^{\prime}$ should be almost constant.

The observed rather weak reduction of $\varepsilon^{\prime}$ with the frequency growth can be a high-frequency interval of lower-frequency relaxation processes associated with the relaxation of molecular dipoles in the polymeric matrix owing to the presence of additives of other substances inserted in the course of matrix fabrication $[47,48]$, the recharge of localized electron states in the regions of the dielectric polymeric matrix adjacent to the conducting filler particles $[30,32]$, or the specimen polarization near the electrode [33].

\subsubsection{Dependences of the dielectric permittivity of composites on the filler volume fraction}

In accrodance with the percolation character of the conductivity and the microstructure topology, the considered composites should be classified to statistical mixtures [41]. The most often, the dielectric properties of the latter are analyzed, by using the Böttcher-Hsu formula [43]. For the complex dielectric permittivity of the studied composite, $\varepsilon^{*}$, this formula can be written as follows:

$\frac{\varepsilon_{\mathrm{C}}^{*}-\varepsilon^{*}}{\varepsilon^{*}+\left(\varepsilon_{\mathrm{C}}^{*}-\varepsilon^{*}\right) A} \nu+\frac{\varepsilon_{\mathrm{PP}}^{*}-\varepsilon^{*}}{\varepsilon^{*}+\left(\varepsilon_{\mathrm{PP}}^{*}-\varepsilon^{*}\right) A}(1-\nu)=0$, where $\varepsilon_{\mathrm{C}}^{*}=\varepsilon_{\mathrm{C}}^{\prime}+\sigma_{\mathrm{C}} / j \omega \varepsilon_{0}$, and $A$ is the depolarization factor for an ellipsoidal particle along the direction of the applied electric field. For spherical particles, $A=1 / 3$.

From Eq. (2), for the low-frequency dielectric permittivity of a statistical mixture, $\varepsilon_{l}$, we obtain

$\varepsilon_{l}^{\prime}=\varepsilon_{\mathrm{PP}}^{\prime} \frac{A}{A-\nu}$.

When deriving this formula, we took into account that $\varepsilon_{\mathrm{C}}^{\prime} \rightarrow \infty$ at $\omega \rightarrow 0$. One can see that, at $\nu \rightarrow A$, the low-frequency dielectric permittivity of a statistical mixture infinitely grows. In other words, the value $\nu=A$ is limiting, and the quantity $A$ corresponds to the percolation threshold, which is designated as $\nu_{\mathrm{C}}$.

Expression (3) allows the value of $\nu_{\mathrm{C}}$ to be estimated on the basis of the dependence $\varepsilon_{l}^{\prime}(\nu)$. The fitting condition for the parameter $\nu_{\mathrm{C}}$ is the approximation of the experimental dependence $\log \left(\varepsilon_{l}\right)$ versus $\log \left(\nu_{\mathrm{C}}-\nu\right)$ by a straight line with a slope close to unity in the volume fraction interval $\nu<\nu_{\mathrm{C}}$ [28, 29, 49].

As a rule, it is rather difficult to experimentally determine the static value corresponding to the Maxwell-Wagner dielectric dispersion because of manifestations of other overlapping dispersion regions. Those regions can be associated with polarization processes in the polymeric matrix component or at its boundaries. However, taking Eq. (3) into account, while analyzing the data for carbon filler particles with different sizes presented in Fig. 4, it is possible to consider the frequency dependences $\varepsilon_{\mathrm{PP}}^{\prime}(f)$ identical for the same $\nu$-values and to put $\varepsilon_{l}^{\prime} \sim \varepsilon_{\mathrm{LF}}^{\prime}$, where $\varepsilon_{\mathrm{LF}}^{\prime}$ is the low-frequency dielectric permittivity of a composite.

In Fig. 5, straight line 1 illustrates the experimental dependence of the low-frequency dielectric permittivity of the studied composites, $\varepsilon_{\mathrm{LF}}^{\prime}$ at the frequency $f=3 \mathrm{MHz}$ on the volume fraction of the carbon filler, $\nu$, in the coordinates $\log \left(\varepsilon_{\mathrm{LF}}^{\prime}\right)$ versus $\log \left(\nu_{\mathrm{C}}-\nu\right)$. The obtained value for $\nu_{\mathrm{C}}$ approximately equals 0.105 . It differs substantially from the theoretical value calculated from the Böttcher-Hsu formula for a mixture of spherical particles. However, it is in agreement with models and estimations made in other works $[27-29,50]$, where the limiting value of the filler volume fraction determined from dielectric measurements (and from conductivity data) is smaller than the indicated theoretical value $\nu_{\mathrm{C}}=1 / 3$.

ISSN 2071-0194. Ukr. J. Phys. 2016. Vol. 61, No. 11 


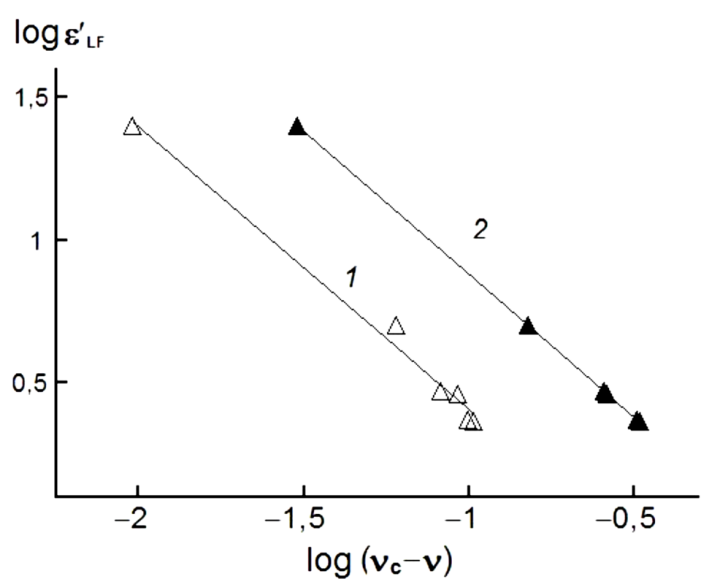

Fig. 5. Dependences of $\varepsilon_{\mathrm{LF}}^{\prime}$ on $\nu$ (1) and $\mathrm{f} \nu_{T H}$ (2) according to the Böttcher-Hsu model for a composite specimen with micro-sized particles of the carbon filler

Figure 5 also demonstrates the dependence $\varepsilon_{\mathrm{LF}}^{\prime}\left(\nu_{T H}\right)$, where $\nu_{T H}=\nu_{\mathrm{C}}\left(1-\varepsilon_{\mathrm{PP}}^{\prime} / \varepsilon_{\mathrm{LF}}^{\prime}\right)$ is the theoretical value for the volume fraction of spherical carbon filler particles, which is determined according to the Böttcher-Hsu model [see Eq. (3)] at $\nu_{\mathrm{C}}=1 / 3$. The most plausible origin of the discrepancy between the indicated dependences may be the presence of interphase transient layers, into which free charge carriers can enter from conducting filler particles. In so doing, they increase the total fraction of a composite volume, where the conductivity is rather high.

\subsubsection{Dependences of the low-frequency} dielectric permittivity of composites on the filler particle size

The dielectric spectra of composites with identical volume fractions of the carbon filler, but different dimensions of filler particles, which are depicted in Fig. 4, b, confirm the hypothesis formulated above and concerning the presence of interphase transient layers, in which free charge carriers can move.

Figure 6 demonstrates that a growth of the specific surface of filler particles, i.e. a reduction of their dimensions, is accompanied by an increase of the lowfrequency dielectric permittivity of composites. As a parameter that characterizes the particle size, we used the specific particle surface $\beta_{S}$. For spherical particles, $\beta_{S}$ can be evaluated, by using the formula $\beta_{S}=6 / a$, where $a$ is the average linear size (diameter) of particles.

ISSN 2071-0194. Ukr. J. Phys. 2016. Vol. 61, No. 11

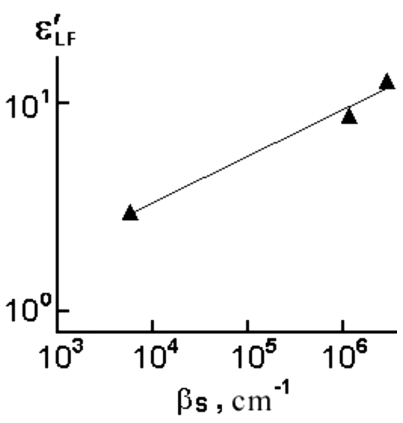

Fig. 6. Dependence of the relative dielectric permittivity $\varepsilon_{\mathrm{LF}}^{\prime}$ at the frequency $f=3 \mathrm{MHz}$ on the specific surface of the carbon filler $\beta_{S}(\nu=0.022)$

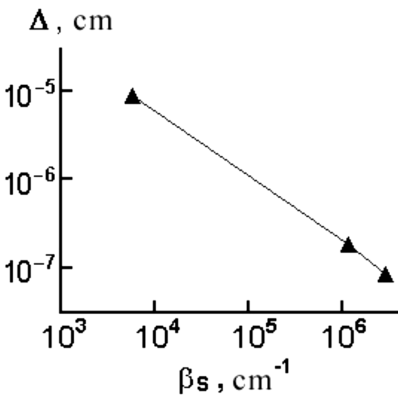

Fig. 7. Dependence of the effective thickness of the interphase layer, $\Delta$, on the specific surface of the carbon filler for the composite with $\nu=0.022$

The effective thickness $\Delta$ of such interphase layer can be estimated on the basis of the difference between the theoretical, $\nu_{T H}$, and technological, $\nu$, values of the carbon filler volume fraction, by using the following relationship: $\nu_{T H}=\nu+\beta_{S} \cdot \Delta$, i.e. by applying the formula $\Delta=\left(\nu_{T H}-\nu\right) / \beta_{S}$. As one can see from Fig. 7, when the specific surface increases (when the average particle size diminishes from $10 \mu \mathrm{m}$ to $20 \mathrm{~nm}$ ), the interphase layer thickness decreases from about 1 to about $5 \mathrm{~nm}$. This result agrees with the results of work [19] that smaller particles destroy the polymer structure to a less extent (they deform it at shorter distances from their boundaries).

\section{Conclusions}

We have found that a reduction of the average size of conducting filler particles in polypropylenecarbon composites under the same other conditions brings about a decrease of the composite specific resistance and a shift of the posistor section in the 
current-voltage characteristics toward lower electric field strengths and higher currents. Those size effects may be a manifestation of the existence of an interphase boundary layer in the polypropylene matrix. The electric properties of this layer differ from those of bulk polypropylene. In particular, free charge carriers can move in it. As a result, the "apparent" volume fraction of the conducting filler in the composite increases. The presence of the indicated layer can give rise to a decrease of the threshold volume fraction of the conducting filler, provided that the percolation is a mechanism of conductivity in the composites concerned.

The dielectric spectra of composites can be interpreted in the framework of the Böttcher-Hsu model, making allowance for the existence of an interphase conducting layer adjacent to the surface of carbon filler particles. The thickness of this layer is estimated. We have determined that it diminishes from $\sim 1 \mu \mathrm{m}$ to $\sim 5 \mathrm{~nm}$, when the size of conducting filler particles decreases from $10 \mu \mathrm{m}$ to $20 \mathrm{~nm}$.

1. R. Löhnert, H. Bartsch, R. Schmidt, B. Capraro, J. Töpfer. Microstructure and electric properties of $\mathrm{CaCu}_{3} \mathrm{Ti}_{4} \mathrm{O}_{12}$ multilayer capacitors. J. Am. Ceram. Soc. 98, 141 (2015) [DOI: $10.1111 /$ jace.13260].

2. H. Cheng, W. Zhou, H. Du, F. Luo, D. Zhu, B. Xu. $\mathrm{MnO}_{2}$-modified $0.98\left(\mathrm{~K}_{0.5} \mathrm{Na}_{0.5}\right) \mathrm{NbO}_{3}-0.02 \mathrm{LaFeO}_{3}$ ceramics with low dielectric loss for high temperature ceramics capacitors applications. Ceram. Int. 40, 5019 (2014) [DOI: 10.1016/j.ceramint.2013.08.095].

3. T.K. Gupta. Application of zinc oxide varistors. J. Am. Ceram. Soc. 73, 1817 (1990) [DOI: 10.1111/j.11512916.1990.tb05232.x].

4. D.R. Clarke. Varistor ceramics. J. Am. Ceram. Soc. 82, 485 (1999) [DOI: 10.1111/j.1151-2916.1999.tb01793.x].

5. A. Glot, G. Behr, Werner. Current limiting effect in $\mathrm{In}_{2} \mathrm{O}_{3}$ ceramics based structures. Key Eng. Mater. 206, 1441 (2002) [DOI: 10.4028/www.scientific.net/KEM. 206213.1441].

6. A. Bondarchuk, A. Glot, G. Behr, J. Werner. Current saturation in indium oxide based ceramics. Eur. Phys. J. Appl. Phys. 39, 211 (2007) [DOI: 10.1051/epjap:2007112].

7. A.B. Glot, S.V. Mazurik, B.J. Jones, A.N. Bondarchuk, R. Bulpett, N. Verma. Current limiting and negative differential resistance in indium oxide based ceramics. J. Eur. Ceram. Soc. 30, 539 (2010) [DOI: 10.1016/ j.jeurceramsoc.2009.06.033].

8. A.B. Glot, S.V. Mazurik. Non-Ohmic conduction in $\mathrm{In}_{2} \mathrm{O}_{3}-$ $\mathrm{Bi}_{2} \mathrm{O}_{3}$ ceramics. Physica B 428, 65 (2013) [DOI: 10.1016/ j.physb.2013.07.017].

\section{4}

9. W. Heywang. Amorphe und Polykristalline Halbleiter. (Springer, 1984) [DOI: 10.1007/978-3-642-95447-4].

10. W. Zhang, A.A. Dehghani-Sanij, R.S. Blackburn. Carbon based conductive polymer composites. J. Mater. Sci. 42, 3408 (2007) [DOI: 10.1007/s10853-007-1688-5].

11. A. Rybak, G. Boiteux, F. Melis, G. Seytre. Conductive polymer composites based on metallic nanofiller as smart materials for current limiting devices. Compos. Sci. Technol. 70, 410 (2010) [DOI: 10.1016/ j.compscitech.2009.11.019].

12. J. Aneli, G. Zaikov, O. Mukbaniani, Physical principles of the conductivity of electrically conductive polymer composites (Review). Mol. Cryst. Liq. Cryst. 554, 167 (2012) [DOI: 10.1080/15421406.2012.633866].

13. Y. Liu, S. Kumar. Polymer/carbon nanotube nano composite fibers - A review. ACS Appl. Mater. Interfaces 6, 6069 (2014) [DOI: 10.1021/am405136s].

14. A.B. Glot, A.M. Makeev. Non-linear electrical characteristics of composite layers conductor-dielectric. Phys. Chem. Solid State 2, 375 (2001).

15. I.A. Morozov, A.L. Svistkov, G.B. Heinrich. Structure of the carbon-black-particles framework in filled elastomer materials. Polym. Sci. Ser. A 49, 292 (2007) [DOI: 10.1134/S0965545X07030091].

16. A. Montazeri, R. Naghdabadi. Investigation of the interphase effects on the mechanical behavior of carbon nanotube polymer composites by multiscale modeling. J. Appl. Polym. Sci. 117, 361 (2010) [DOI: 10.1002/app.31460].

17. J. Fröhlich, W. Niedermeier, H.D. Luginsland. The effect of filler-filler and filler-elastomer interaction on rubber reinforcement. Composites Part A: Appl. Sci. Manufact. 36, 449. (2005) [DOI: 10.1016/j.compositesa.2004.10.004].

18. S.Y. Fu, X.Q. Feng, B. Lauke, Y.W. Mai. Effects of particle size, particle/matrix interface adhesion and particle loading on mechanical properties of particulate-polymer composites. Composites Part B: Engineering 39, 933 (2008) [DOI: 10.1016/j.compositesb.2008.01.002].

19. A.N. Rassokha, A.N. Cherkashyna, T.I. Chramova. Influence of the interphase layer origin on the properties of furan-epoxy composites. Integr. Technol. Ener. Conserv. 2, 124 (2011).

20. K.T. Chung, A. Sabo, A.P. Pica. Electrical permittivity and conductivity of carbon black-polyvinyl chloride composites. J. Appl. Phys. 53, 6867 (1982) [DOI: 10.1063/ 1.330027].

21. Ye.P. Mamunya, V.V. Davydenko, P. Pissis, and E.V. Lebedev. Electrical and thermal conductivity of polymers filled with metal powders. Eur. Polym. J. 38, 1887 (2002) [DOI: 10.1016/S0014-3057(02)00064-2].

22. L. Cui, Y. Zhang, Y. Zhang, X. Zhang, W. Zhou. Electrical properties and conductive mechanisms of immiscible polypropylene/Novolac blends filled with car-

ISSN 2071-0194. Ukr. J. Phys. 2016. Vol. 61, No. 11 
bon black. Eur. Polym. J. 43, 50976 (2007) [DOI: 10.1016/j.eurpolymj.2007.08.023].

23. W. Bauhofer, J.Z. Kovacs. A review and analysis of electrical percolation in carbon nanotube polymer composites. Compos. Sci. Technol. 69, 1486 (2009) [DOI: 10.1016/j.compscitech.2008.06.018].

24. S.G. Shin. A study on the percolation threshold of polyethylene matrix composites filled carbon powder. Electron. Mater. Lett. 6, 65 (2010) [DOI: 10.3365/ eml.2010.06.065].

25. G.M. Tsangaris, G.C. Psarras, N. Kouloumbi. Electric modulus and interfacial polarization in composite polymeric systems. J. Mater. Sci. 33, 2027. (1998) [DOI: 10.1023/A:1004398514901].

26. G.C. Psarras, E. Manolakaki, G.M. Tsangaris. Dielectric dispersion and ac conductivity in - Iron particles loaded polymer composites. Composites Part A 34, 1187 (2003) [DOI: 10.1016/j.compositesa.2003.08.002].

27. J. Zhang, M. Mine, D. Zhu, M. Matsuo. Electrical and dielectric behaviors and their origins in the threedimensional polyvinyl alcohol/MWCNT composites with low percolation threshold. Carbon 47, 1311 (2009) [DOI: 10.1016/j.carbon.2009.01.014].

28. S.-G. Shin, I.-K. Kwon. Effect of temperature on the dielectric properties of carbon black-filled polyethylene matrix composites below the percolation threshold. Electron. Mater. Lett. 7, 249 (2011) [DOI: 10.1007/s13391-0110913-1].

29. Y. Dang, Y. Wang, Y. Deng, L.I. Mao, Y. Zhang, Z.W. Zhang. Enhanced dielectric properties of polypropylene based composite using $\mathrm{Bi}_{2} \mathrm{~S}_{3}$ nanorod filler. Prog. Nat. Sci.: Mater. Int. 21, 216 (2011) [DOI: 10.1016/S10020071(12)60033-1]

30. A.S. Tonkoshkur, S.F. Sklyar, E.F. Afonko. Effect of built-in charge on dielectric phenomena in inhomogeneous matrix-type structure. Russ. Phys. J. 31, 108 (1988).

31. M.C. Righi, S. Scandolo, S. Serra, S. Iarlori, E. Tosatti, G. Santoro. Surface states and negative electron affinity in polyethylene. Phys. Rev. Lett. 87, 076802 (2001) [DOI: 10.1103/PhysRevLett.87.076802].

32. A.V. Degtyar'ov, A.S. Tonkoshkur, A.Yu. Lyashkov. Electrical properties of posistor composite materials based on polyethylene-graphite. Multidisc. Model. Mater. Struct. 2, 435 (2006) [DOI: 10.1163/157361106778554897].

33. N.A. Drokin, G.A. Kokourov, G.A. Glushchenko, I.V. Osipova, A.N. Maslennikov, G.N. Churilov. Effect of electrode material on impedance spectra of metal-polyethylene structures with carbon nanotubes. Phys. Solid State 54, 844 (2012) [DOI: 10.1134/S1063783412040063].

34. V.R. Kolbunov, A.S. Tonkoshkur, K.V. Antonova. Structure and dielectric properties in the radio frequency range of polymer composites based vanadium dioxide. Tekhnol. Konstruir. Elektr. Apparat. 2-3, 47 (2015) [DOI: 10.15222/TKEA2015.2-3.47].
35. M.F. Wartenberg, J.G. Lahlouh, J. Toth. Patent US5747147 MKI B32B9/00 Conductive polymer composition and device: No. 19970130; Publ. 05.05.98.

36. B.I. Shklovskii, A.L. Efros. Electronic Properties of Doped Semiconductors. (Springer, 1984) [DOI: 10.1007/978-3662-02403-4_3].

37. P.G. De Gennes. On a relation between percolation theory and the elasticity of gels. J. Phys. Lett. 37, 1 (1976) [DOI: 10.1051/jphyslet:019760037010100].

38. A.K. Jonscher. Admittance spectroscopy of systems showing low-frequency dispersion. Electrochim. Acta 35, 1595 (1990) [DOI: 10.1016/0013-4686(90)80015-G].

39. F. Kremer, A. Schönhals. Broadband Dielectric Spectroscopy (Springer, 2003) [DOI: 10.1007/978-3-642-561207_3].

40. S. Wróbel, B. Gestblom, J. Jadżyn et al. Dielectric relaxation spectroscopy, in Relaxation Phenomena (Springer, 2003), p. 13 [DOI: 10.1007/978-3-662-09747-2_2].

41. S.S. Dukhin, V.N. Shilov. Dielectric Phenomena and the Double Layer in Disperse Systems and Polyelectrolytes (Wiley, 1974).

42. A.S. Tonkoshkur, I.M. Chernenko. Effect of surface electrical conductivity on dielectric characteristics of polydisperse semiconductors. Sov. Phys. J. 19, 1407 (1976) [DOI: 10.1007/BF00890783].

43. G. Banhegyi. Numerical analysis of complex dielectric mixture formulae. Colloid. Polym. Sci. 266, 11 (1988) [DOI: 10.1007/BF01451527].

44. Polypropylene Handbook: Polymerization, Characterization, Properties, Processing, Applications, edited by E.P. Moore et al. (Hanser Publ., 1996) [ISBN-10: 1569902089].

45. A.G. Betekhtin. A Course of Mineralogy (Mir Publ., 1967).

46. D.C. Giancoli. General Physics (Prentice-Hall, 1984).

47. P. Fischer, P. Röhl. Thermally stimulated and isothermal depolarization currents in low-density polyethylene. J. Polym. Sci. B 14, 531 (1976) [DOI: 10.1002/pol.1976.180140313].

48. J. Orrit, J.C. Canadas, J. Sellares et al. Identification of dipolar relaxations in dielectric spectra of mid-voltage cross-linked polyethylene cables. J. Electrostatics 69, 119 (2011) [DOI: 10.1016/j.elstat.2011.01.005].

49. V. Panwar, J.O. Park, S.H. Park, S. Kumar, R.M. Mehra. Electrical, dielectric, and electromagnetic shielding properties of polypropylene-graphite composites. J. Appl. Polym. Sci. 115, 1306 (2010) [DOI: 10.1002/app.29702].

50. J.K. Yuan, S.H. Yao, A. Sylvestre, J. Bai. Biphasic polymer blends containing carbon nanotubes: heterogeneous nanotube distribution and its influence on the dielectric properties. J. Phys. Chem. C 116, 2051 (2012) [DOI: $10.1021 / \mathrm{jp} 210872 \mathrm{w}]$.

Received 20.06.16.

Translated from Ukrainian by O.I. Voitenko 
О.С. Тонкошкур,

О.Ю. Ляшков, А.В. Дегтяръов

РОЗМІРНІ ЕФЕКТИ

В ЕЛЕКТРИЧНИХ ВЛАСТИВОСТЯХ

ВУГЛЕЦЕВО-ПОЛІПРОПІЛЕНОВИХ КОМПОЗИТІВ

$\mathrm{P}$ е 3 ю м е

Наведено температурні залежності опору, вольт-амперні характеристики й діелектричні спектри композитів на основі поліпропілену й наповнювачів з мікро- і нанорозмірних вуглецевих частинок. Зменшення середнього розміру частинок провідникового наповнювача при інших однакових умовах приводить до зменшення абсолютних значень питомо- го електричного опору; зсуву позисторної ділянки вольтамперної характеристики убік меншої напруженості електричного поля й більших струмів і зростання низькочастотної діелектричної проникності досліджених композитів. Показано, що однією з інтерпретацій прояву такого "розмірного" ефекту можуть бути уявлення про збільшення ефективної об'ємної долі провідникового наповнювача внаслідок існування в поліпропіленовій матриці міжфазного прикордонного шару з відмінними від об'ємного поліпропілену електричними властивостями, у якому можливе переміщення носіїв заряду. Тобто зміни розміру частинок вуглецю ведуть до змін питомої поверхні та ефективної долі провідникового наповнювача. 